\title{
Perspectives of husbands of women with breast cancer: Impact and response
}

\author{
By Margaret I. Fitch and Marc Allard
}

\section{Abstract}

When breast cancer is diagnosed, it has the potential to have an impact on a woman's partner and influence how the male partner can support the woman. This qualitative study was undertaken to explore the impact on male partners of having a wife who has been diagnosed with breast cancer. In-depth interviews with 15 husbands provided a rich sense of the nature of the impact and how these men responded to it. Analysis revealed two overarching themes: 1) the diagnosis was shocking and unexpected, and 2) the impact of breast cancer on the male partner is wide-ranging. The respondents described a wide range of changes that had occurred in their lives since the unexpected, shocking diagnosis. They shared vivid accounts of personal emotional reactions, changes in daily work life and household responsibilities, worries about children, and changes in their relationships with their wives. They experienced ongoing struggles to balance the demands within their lives. Two significant challenges these men described were coping with work-related demands and sorting out how to be supportive to their wives. Clearly, the breast cancer diagnosis had an impact on these men and created personal tension for them. Cancer nurses need to be aware of this impact, acknowledge the sense of vulnerability it can create in male partners, and work to find effective ways to support them.

When a woman is diagnosed with breast cancer, there is more than a physical impact. A cancer diagnosis and its subsequent treatment also have emotional, psychological, social and practical consequences (Moyer \& Salovay, 1996; Rees \& Bath, 2000; Raupach \& Hiller, 2002). It is an ongoing challenge for women to experience these consequences and cope with the subsequent impact on their lives. Often, they turn to their partners for support.

However, when cancer strikes, the male partners also feel the impact and face the challenges. They, too, experience emotional and psychological reactions and must cope with the consequences. No doubt, how they manage to deal with these challenges and adjust to the changes will have an influence on how the woman deals with her illness.

To date, relatively little is known about the nature of the impact on male partners when a wife is diagnosed with cancer and subsequently treated for the disease. Understanding that impact from their perspective would increase the likelihood of appropriate interventions being designed.

This study was undertaken to explore the impact on male partners of having a wife who has been diagnosed with breast cancer. In-depth interviews provided a rich sense of the nature of the impact and how the men responded to it. The insight they provide offers a foundation to design interventions or approaches to support individuals in similar situations.

\section{Background}

During the past 15 years, there has been a substantial increase in the amount of quantitative information about the impact of a woman's diagnosis of breast cancer on a partner and family. There is an unequivocal recognition that cancer is a family experience (Yates, 1999). The body of knowledge supporting this view has grown over these years through four discernable stages (Lewis, 2004). The early and first phase focused on the impact of psychosocial morbidity in the women and its ramification for the partners using quantitative measures. This phase served to raise awareness about the desirability of including the partner in conversations about treatment and in decision-making (Ervin, 1973; Kent, 1975; Wellisch, Jamieson, \& Pasnau, 1978; McGuire, 1981).

The second phase of research looked to measure psychosocial distress in both women diagnosed with the disease and in the partners (Oberst \& James, 1985; Northouse, 1988; Northouse \& Swain, 1987). This was the point in time when the partner's distress was recognized as being as high, if not higher than the women's (McGuire, 1981; Baider \& De-Nour, 1984).

Subsequently, the third phase of the research saw statistical modelling techniques applied to test hypotheses about breast cancer impact on the family (Lewis, Woods, Hough, \& Bensley, 1989; Lewis, Hammond, \& Woods, 1993; Woods \& Lewis, 1995; Lewis \& Hammond, 1996). Based on these empirical studies, The Relationship Model of Family Function with Cancer (Lewis, et al., 1993) has been offered as a framework for utilization in oncology nursing practice. It is based on cancer as a psychosocial transition in which family members work to find a balance in their ongoing life as a family. When illness strikes a patient, the family is required to maintain stability in its routine internal arrangements and activities as well as restructure its interactions and activities to manage the ongoing demands of the illness (Yates, 1999).

Although nurses need to respond to the entire family as a unit, they also need to be able to respond to the individual members. An important first step in being able to respond appropriately to individual members is to understand the nature of the impact upon those individuals from their perspectives. Much of the qualitative work describing the nature of the impact of breast cancer has focused on the perspectives of women about their experiences and women's ideas about the impact on their partners (Samms, 1999; Hilton, Crawford, \& Tarko, 2000). What is needed is a similar body of knowledge describing the impact of breast cancer from the male partners' perspectives about their experiences. To describe the nature of the impact as it is seen from the viewpoint of the men themselves requires a qualitative approach.

\section{Purpose}

This study was undertaken to explore the perceived impact of a breast cancer diagnosis on male partners of women diagnosed and treated for breast cancer. The aim of the work was to generate an

Dr. Margaret Fitch, Toronto Sunnybrook Regional Cancer Centre, Toronto, $O N$.

Marc Allard was a second-year medical student at the time of the study and is continuing his studies at the University of Toronto.

E-mail: marg.fitch@sunnybrook.ca 
enlarged understanding of the impact the men felt during this experience of breast cancer and their response to that impact. It was anticipated the data would help to determine if specific interventions ought to be designed for men facing this life event.

\section{Methods}

This descriptive qualitative study made use of in-depth interviews to explore men's experience with having a wife diagnosed and treated for breast cancer. The open-ended interview questions asked the participants to describe the events surrounding the breast cancer diagnosis and treatment, their responses to those events, the information they sought, and how they managed to adjust and cope with what occurred. If the participant did not mention the topics on his own, specific probes were used to ask about changes (i.e., at work, in his daily life, in his relationship, and within himself) that occurred because of the breast cancer.

Following ethical approval for the study by Sunnybrook and Women's College Health Sciences Centre Research Ethics Committee, men were accrued by sending invitations to each of the member support groups of the Ontario Breast Cancer Information Exchange Partnership (OBCIEP). The member agencies distributed the invitations to their members (women living with breast cancer) who shared them with their partners. To be eligible, a man had to be a partner of a woman diagnosed with breast cancer preferably in the past two years and be able to speak English. However, if a man took the initiative to call and was willing to be interviewed, we included him. Interested individuals contacted the OBCIEP office and the research assistant explained the participation in detail.

Once the individual had consented to participation, all the interviews were conducted by the research assistant over the telephone and audiotaped. Consent forms were sent to participants for signature prior to the interview, together with a copy of the interview guide. The interviewer was a male medical student prepared to conduct the interviews. The interviews lasted between 30 and 60 minutes. The interviews were open-ended and began by asking participants to describe the events surrounding the diagnosis and treatment of their partner's breast cancer. Subsequently, they were asked about the concerns or questions they had, their search for information, and how they thought health care professionals could improve the situation.

\section{Analysis}

The interview audiotapes were transcribed verbatim and subjected to a content analysis (Silverman, 2000). The analysis was conducted with a view to understanding and describing the impact these partners experienced. The investigators read each of the interviews separately and made marginal notes about the content in each interview. The investigators subsequently compared their notations about the full

\begin{tabular}{|l|l|l|}
\hline \multicolumn{3}{|c|}{ Table One. Selected demographic characteristics $(\mathbf{N}=15)$} \\
\hline Age in years (participants) & $\begin{array}{l}\text { average (SD) } \\
\text { range }\end{array}$ & $\begin{array}{l}53( \pm 11.89) \\
34-71\end{array}$ \\
\hline Age in years (wives) & $\begin{array}{l}\text { average (SD) } \\
\text { range }\end{array}$ & $\begin{array}{l}47( \pm 10.37) \\
33-64\end{array}$ \\
\hline Years married & $\begin{array}{l}\text { average (SD) } \\
\text { range }\end{array}$ & $25( \pm 12.56)$ \\
& $<10$ years & 5 \\
\hline Number with children & $>10$ years & 11 \\
\hline Number retired (participants) & & 3 \\
\hline Time since diagnosis (wives) & average (yrs) & 3.06 \\
& range & $0.5-19$ \\
\hline
\end{tabular}

range of content and agreed upon a coding categorization. One investigator then completed the coding of the content in all interviews (MF). Each coded category was reviewed and the content within each was summarized. Review across all categories was then undertaken to identify the key ideas (themes) that would reflect across the content categories. These overarching key ideas are used to frame the description of the findings below.

\section{Findings}

\section{Selected characteristics}

A total of 15 husbands participated in this study. Three lived in Toronto, three in Peterborough, and nine in Ottawa. All were living with their wives at the time of the interviews. Selected demographic information about both the participants and their wives are presented in Table One.

\section{The diagnosis was shocking and unexpected}

Without exception, the participants described learning about their wife's diagnosis of cancer as shocking and terrifying. While some had had an experience of breast cancer in other family members, and others were aware of breast cancer through the media, they all felt caught "off guard." They were not expecting breast cancer to be diagnosed in their wife. Their initial thoughts were predominantly about the possibility of losing their wife, especially if they knew little about breast cancer and its treatment options.

It was a real shock to find out the lump in her breast was breast cancer. A real shock. We weren't expecting it at all... at first, I thought she was going to die, that I'd lose her. (15)

When I first learned she had breast cancer, I was really worried, because my sister-in-law had died of breast cancer. (8)

The participants described the initial period after learning about the diagnosis as a very difficult time. Undergoing diagnostic tests and waiting for surgical procedures and results were stressful times, but once participants learned the diagnosis was definitely cancer, the stressful feelings escalated. Many felt overwhelmed, helpless, and not sure what to do.

It was devastating. Just devastating. There is no other word for it. We were both so overwhelmed... I felt helpless to do anything. I didn't know what to do. (7)

It was a terrifying experience. Horrifying. Definitely shocking. The whole time following the time we learned about the diagnosis was a complete daze. That first week was just a daze... the word itself scared me because I just lost my Dad because of cancer a year ago. (9)

When the diagnosis was a recurrence of the disease, participants felt more uncertainty and worry about their wife's future than with the initial diagnosis. They were facing the recurrent diagnosis with more information about breast cancer and its treatment than the first time the diagnosis was made and it served to heighten their feelings of concern.

This whole situation, this whole experience has been quite upsetting. I really thought she would beat this. But it has not happened. At first I did not really understand how serious it was. I really thought it could be treated. Now I am not so sure. The disease has come back two times and has gotten into her lungs. (4)

This is her second one. So that changes things quite a bit. With the first cancer, we were quite optimistic. But with this being the second cancer, there is a lot of uncertainty. With this second one, she is much more fatalistic, and this really gets me down. (10)

A small number of participants did not express the same intensity of shock or dismay as the others. For them, specific factors played a role in their responses - learning the disease was not as extensive as they had first believed or being focused on dealing with problems of their own. For example, one participant stated: 
I am not too concerned about the disease. I feel everything is going to be fine and the disease will not come back. My wife is really quite strong and keeps a lot to herself... maybe because I have some health problems of my own. (8)

\section{The impact of breast cancer on the male partner is wide-ranging}

When asked about the impact of their partner's breast cancer diagnosis and treatment on themselves, the men in this study described a wide range of changes that had occurred in their lives since the diagnosis had been made. Their descriptions contained vivid accounts of 1) emotional reactions, 2) changes in daily responsibilities and work life, 3) worries about children, and 4) changes in relationship with their partner and intimate relationships. Their accounts illustrated the potential for breast cancer to have an impact on many aspects of a partner's life; it can have a ripple effect as the experience pervades the lives of the whole family. Each of these content areas will be described below.

\section{Emotional reactions}

The partners in this study described a wide range of emotional reactions about having a wife diagnosed with breast cancer: sadness in having to watch his partner go through the situation, helplessness about what he could actually do to help, and anger about what was happening. In one partner's words:

When she was first diagnosed, I was so angry, really angry that she had got this, that she had to get this and have to go through all the treatments. I was really angry that the children would have to go through all this, too. I guess I was also sad that this had to happen to us, like it was not fair. (12)

Another partner likened his sense of helplessness to the way he felt during childbirth:

There is such a real feeling of helplessness about it all. It's sort of like childbirth, you sit on the sidelines and there is nothing you can do. It's like, well, helplessness, like what can you do that will really make a difference? (5)

These partners described struggling with thoughts about the situation being unfair and wondering how it could have happened to their wives and to them. Many had questions about the disease occurring in young women, why it was identified seemingly only by chance, and why chemotherapy was recommended when it was so difficult to take, yet had such a small impact on the chance of recurrence. Overall, most men indicated they had difficulties because they felt quite unprepared for the situation and uncertain about how they could help.

\section{Changes in daily responsibilities}

Once treatment began, participants often found themselves caught up in a whirlwind of activities and daily responsibilities concerning the treatment, their family and the household chores. This was especially the case when there were young children in the family. In some cases, this was new activity for the partner, while for others it was an intensification of an activity he already performed. For many, the struggle was to balance or juggle all the demands placed upon them.

I am really not sure how all of this is affecting me. I just know it is... some day I'll figure it all out. But right now there is so much to deal with each day, I just have to keep moving. (12)

I feel like I have been on the verge of collapse for two years... I have no personal time... no time to look after myself. It's really a joke when people say to take care of myself. Like how am I supposed to do that? It's like goodbye to your own life. (13)

I find a lot of the time I am really quite tired. I find it's hard to work in the kitchen after working all day at the office. (11)
The participants who experienced less struggle with these daily demands were older, had retired from work, or did not have young children at home. For example,

I really did not feel much of an impact on my day-to-day life. I think it would probably have been different if I had been working at the time. I felt I needed to be there 24 hours a day for her and I could not have done that if I had still been working. (7)

I do not think there was much, too much of an impact day-to-day, really. I did not have to take on anything like extra responsibilities with children or around home. (14)

\section{Worried about children}

The men with young children described how difficult they found it to care to the children when their mother was ill and to talk with the children about the illness. They struggled with what to tell the children, when to tell them, and what words to use. They found the ages of the children and the number of children in the household added to the complexity of the communication. Older children were described as more independent and able to look after themselves, although older daughters presented concerns because of their own emerging worries about also developing breast cancer.

The kids were older, in their teens, and so the whole household thing was not such an issue for them. I guess the biggest issue was my daughter. She really was concerned about her prospects and wondered if she'd get breast cancer now. (1)

We found it really hard to figure out what to say to the children, to answer their questions about what was happening with their mother. Usually she's at home with them all the time, and now she's not, and their grandmother is here. They're just three and five. (5)

Dealing with the children was hard. Getting them through each day and night. I had a lot of trouble with the baby waking up through the night so much. (13)

I worry about the children. How will I be able to care for them without her? I comb my daughter's hair and think, what if it has knots and I can't get the knots out? (9)

\section{Changes in work-related demands}

One of the significant challenges for the men was coping with work-related demands. In all cases where the partner was not retired, these men were the primary breadwinners in their families. Their capacity to adjust their work schedules and/or workload without compromising their careers had a substantial impact on their ability to be supportive to their wives and to meet their own personal expectation about being available for their wives. Many talked about changing their work days and hours, taking leaves, using vacation time, and working via computer at home as necessary adjustments. Whether or not an employer was understanding of the situation at home was a crucial factor in making it all manageable.

Since I had my own business, my work is flexible. I had to rearrange my schedule and make up for lost time somewhere else. (14)

At first, I really could not go to work at all, until the chemotherapy was over... it really helped to have an understanding employer. It made a big difference. And my job is a flexible one, I had flexible hours. There really was no risk to my job. I wasn't worried about putting that at risk. And to keep up, I'd just work on the weekends and put in extra time then. (5)

Despite their best efforts, the adjustments they made did not always work out well. Their sense of competing priorities was heightened.

I'd say the whole thing has had a drastic effect on my life. It is particularly difficult because I work shifts and they run through really important, critical times of the day when the kids need help. I have to 
change things to be there for them. My performance at work has really been affected sometimes. Some days are just too much... and I know I've been passed over for promotion... (9)

I was doing more and more to pick up the slack. I took over her paperwork. We had a home business together. I also took over her chores, more and more. She just didn't have the energy for it all... we've lost money, so it's hard financially... and it all really cut into my sleep time. I am sleeping rather poorly because I am always thinking about it all... I mean we still have a business to run. You can't just walk away from it. (2)

\section{Changes in the relationship with their wife and intimacy}

Discussing changes that had occurred in their relationship with their wife since the diagnosis resulted in these men talking about body appearances and the loss of a breast, intimacy and the sense of closeness they felt, the communication between each other, and the challenge of knowing how to be supportive to their wife.

Most of the men in this study indicated the actual loss of the breast was not an issue for them as appearance had not been a priority for them in their relationships. Prior to the surgery, some had harboured concerns about the anticipated loss, what the scar would look like, and what their reaction might be. However, at the time of the interview, all but one of the men had put these concerns behind them. They found it had been helpful knowing what would happen and being prepared for the appearance of the surgical area. It had also helped that the surgery was minimally invasive.

I really don't have any concerns about the loss of her breasts. I mean, she is still the same person. I was sort of prepared for it because her sister had breast cancer 10 years ago. I sort of knew what to expect. So it wasn't really a shock to me. (11)

Men also found it had helped to think about comparing the loss of the person to the loss of a breast. This type of comparison served to focus them on what was important to them and focus on the woman's personality (personhood) or inner beauty. Many expressed the wish breast cancer had not been diagnosed and surgery had not happened, but they knew they had to face the reality that it had and felt the need to move on.

I really wondered at first if I could get over the loss of her breast. You know, get used to it. I wasn't sure I could accept it. It was all rather a shock and I really wondered how it would be, her without a breast and how comfortable we would be. Then I thought, you know, this is silly, a childish way of looking at it. I mean, as I said, it's better than the alternative. (10)

The one man who was still struggling with the loss of the breast at the time of the interview was also using similar cognitive coping approaches. However, his words implied he was still in transition and working through his responses:

The physical deformity of the breast being removed was quite shocking. I can't think of any other word to describe it. In fact, I still find it so. I really have not accepted it. I do, I know I need a wife that is alive and kicking - there is no point in having a dead wife with two breasts - I guess in the end you learn breasts are really not that important. (13)

A point of tension for some of these men was an awareness that there was a difference in the perspectives they held about the loss of the breast and the perspectives their wives held. For example,

I think she is having trouble and having some difficulty with it all and really accepting that I am comfortable with the changes in her body. I wonder if, in her mind, we are a little distant. (12)

My wife, I know she thinks of her breast as being deformed. But it really doesn't bother me. Really, when you think about it, it is just a breast; it is not your personality. (2)
The men in this study talked rather separately about the physical act of intercourse (sex) from the relationship or sense of closeness they felt toward their wives. With regard to sex, their descriptions ranged from, "there's been no change" $(3,11)$ to, "I'd say the sex is better because we are closer" (13). However, participants also described a transition or period of adjustment that had occurred.

Sexually, at first, the first couple of times things were difficult. But after that, things were fine. (1)

Sex is really not all that important in our relationship. I was sort of shocked by her appearance at first, but then I sort of got used to it. You starting thinking, well this is better than the alternative. (10)

A few of the participants described a definite deterioration in their physical relationship.

Things have changed sexually since the surgery. I mean, we have gone from having sex quite a lot to not having it very much. She says it affects her the next day, so she does not want to have sex much (15).

Sexually things have changed. She is a bit distant. I think she is more uncomfortable and a bit cooler. Instead of concentrating on us, she is concentrating on it. (12)

Our relations are zero. They've been brought down to zero with all the chemotherapy and the surgery. The reconstruction surgery caused a lot of sensitivity and immobility. I wonder at this point if it will ever return... we went through this a couple of years ago when she had a bout of depression. It's tough on both of us. (9)

These same individuals who experienced changes in their physical relationships also described changes in their feelings of closeness and in their communication with their wives.

I feel like she is drawing away. She spends so much time and energy involved in support groups. She is becoming attached to them, emotionally attached to them. She's more separated from me in that sense. There's sort of a cooling between us... I see less of her now. (15)

It's really hard to talk about our relationship right now. It had already gone through tremendous pressure, a lot of strain because my wife went through a period of depression... we were just getting along better. On the upswing, and now this happened. (9)

For the most part, the men in this study talked about the relationship with their wives as having become closer than it was before. They discovered the possibility of losing their partner made them think about what was important to them. There was a sudden (acute) realization about how hard it would be to lose this person.

This kind of situation reaffirms your commitment to your wife. You really stop and think about what's important. (14)

The men thought the increased sense of closeness came about because they were spending more time together, talking more with one another, and working things out together. For some, there was a sense they had been taking some aspects of their relationship for granted and the adversity brought that realization to the surface for them.

This whole thing has really strengthened our relationship. We are probably closer now than we ever have been...we worked through things together and tried to support each other by keeping the lines of communication open... I tried to really listen to her, take care of her by listening and to be as available as possible. It was what I could do. (1)

I'd say we were always close, but now I think we are closer than ever, you know. If that's possible. We really worked through things together, you know, when things got tough and difficulties arose. We worked at it together. (2) 
I'd say I love her more than ever. I appreciate her more. When you are married this long [44 years] you can start to take things for granted. And this experience really made me appreciate her more. It resets your priorities. (7)

This sense of enhanced closeness could even exist in light of a decreased physical relationship.

In many ways, I'd say that this experience brought us closer together. I'd say that she knows for certain that I am there for her and I know she's there for me. She knows I've made her my priority. (12)

Communication between the partners was seen as a vital part of the relationship and what influenced the sense of closeness between the couple. Here, too, men identified there had been a sense of transition. The upheaval of the diagnosis and treatment and lack of access to information about prognosis prevented some types of conversation until later in the cancer experience.

Yes, I'd say we talked about things. But we had to do it after, had to wait until she'd gotten over the shock. And me, too. After a while, we could talk about the cancer, and what it could mean to us. Then it wasn't so hard to talk about it all. (2)

\section{Supporting their wives}

A challenge for these men was sorting out how to be supportive to their wives. They felt the need to be helpful and provide support, but were uncertain exactly what to do much of the time. Many accompanied their wives to appointments, took time off work to be with her, took on more chores at home, and searched out information. However, all struggled with the emotional and communication aspects of supporting their wives.

I find it particularly hard to deal with her emotions. I want to help her, to support her, but what do I say or do? I want to show her I understand, or at least I think I understand, but I'm not sure how to do that. (12)

I wanted to be helpful, supportive, but it was hard to know what to say. My wife reacted to things I'd say in a negative fashion, even when I thought I was being supportive and saying the right things. (15)

I find she gets upset pretty easily. I have to be careful, more careful. I am trying to be less confrontational and try to work around the areas of disagreement, try not to get worked up over minor little things. (6)

Despite the challenge, these partners tried to reach out and made attempts to cross the emotional chasm.

To help her out, I gave her lots of hugs. (7)

I tried to help her by just being there, being around the house, talking if she wanted, giving her a shoulder to cry on. She really needed, the biggest thing she needed was to sort out her feelings, to have some space to sort those out. (5)

One strategy these men identified as a way of supporting their wives was projecting optimism and confidence about reaching a positive outcome. However, using this strategy was not without its own struggle.

I felt the best thing I could do was project confidence, a feeling of confidence, and a sense that all was going well. But it was hard sometimes to believe it and to do it. (2)

I try to help her by supporting her, easing her fears, I guess. I try to keep her positive, talking about positive outcomes, you know, the good things we want, trying to be optimistic about it all and telling her to be, too. (13)

Our attitudes are different. I have the idea that as long as you're alive and kicking, you keep going. She is just scared of it. I try to help her, to alleviate her fears, but that's a frustration for her. (14)
Regardless of the variation in emotional responses and in the degree of struggle these men experienced managing the demands of the situation, they found themselves reflecting about their life priorities. The situation evoked a sense of being drawn up short or stopped in their life journey. They were left with questions about where their energies needed to be placed and what was important to them and for their family.

When I think about what we have been through, it was physically and mentally tiring... it was physically and mentally draining ... it is definitely a reality check. (2)

I wasn't really prepared, didn't feel prepared for any of this. Basically, everything that has happened, it makes you re-evaluate your priorities and think about what is best for your family. (9)

\section{Discussion}

The findings of this study contribute new insights to the knowledge base about the impact breast cancer has on husbands of women who are diagnosed with the disease. The findings offer additional evidence that there is a clear and widespread impact on the husband and that impact creates challenges. Clearly, there are emotional, practical, and psychosocial consequences for partners when breast cancer strikes. The men in this study are self-selected and accrued through the breast cancer support group network. These men were able to talk about the issues. They may be different in some ways from others who have wives diagnosed with breast cancer, but who have not been part of support group activity.

The initial emotional reactions described by the men in this study are very similar to those described by women themselves (Luker, Beaver, Leinster, \& Owens, 1996). Their responses are in keeping with expected reactions to a life-threatening event that involves an individual with whom there is a strong emotional bond. The strength of the emotional reaction, and the admissions of personal vulnerability and helplessness raise questions about the husbands' capacity to receive information and participate easily in decisionmaking, especially at the time of initial diagnosis.

This study begins to reveal the nature of the struggles or types of challenges men confront when their wife is diagnosed with breast cancer. The findings emphasize the struggle men had in dealing with the day-to-day activities. Circumstances such as the age of the children, access to family support, freedom to adjust work schedules, and the status of the man's own health influenced the type of demands the men had to handle, as well as the resources on which they could draw (Lethborg, Kissane, \& Burns, 2003). The findings created a picture of struggle and tension in balancing demands in the situation, yet gave no clear idea about whether help had been requested, offered, or accepted in most cases. This is a limitation in the interviewing, but also raises an interesting observation that these men did not describe help-seeking. There was a strong picture of being self-reliant and of the family unit looking after itself. It would be interesting to know the women's perspective of this same scenario.

There was also struggle and tension evident for these men in knowing how to support their wives emotionally. They felt the desire to be supportive, but were left with a sense of not knowing how to be effective in showing that support. One is left with the notion that the normal or usual patterns of interaction had been disrupted or seen as insufficient somehow given the appearance of a life-threatening event in the family. Somehow, the appearance of breast cancer and its ramifications called for something "new" or "different" than had existed in the past. Similar notions were identified by Samms (1999) who linked expectations stemming from the male gender role as guiding husbands' attempts to be supportive.

Despite the struggle, many of these men felt there had been an increased sense of closeness with their wives. As they moved through the adversity and struggle together, it brought about a heightened sense of connectedness. Realization and acknowledgement of the care each felt for the other, and showing their care for each other and for what was important in their lives together, contributed to the heightened 
sense of closeness. This positive aspect of the cancer experience has also been identified by women with breast cancer (Gray, et al., 1998) and women with ovarian cancer (Fitch, Gray, \& Franssen, 2001).

\section{Implications for practice and research}

The findings of this study have several key implications for cancer nurses. Firstly, nurses need to be aware of the impact and sensitive to what the partners may be experiencing throughout the cancer experience. Rather than focusing entirely on the woman, the partners ought to be considered and included as well. Nurses need to have focused conversations with the partners to assess how the partner is feeling and identify any questions they may have. These conversations may need to be conducted with the partner alone. Also, it is important not to assume the men will hear everything that is said by health care professionals the first time or be able to comprehend the medical language.

Secondly, as the woman is undergoing treatment, nurses ought to consider how the household management will occur. Checking routinely with the man or the woman about how the household and

\section{References}

Baider, L., \& De-Nour, A.K. (1984). Couples' reactions and adjustment to mastectomy: A preliminary report. Journal Psychiatry in Medicine, 14, 265-76.

Ervin, J. (1973). Psychological adjustment to mastectomy. Medical Aspects of Human Sex, 7, 42-65.

Fitch, M.I., Gray, R.E., \& Franssen, E. (2001). Perspectives on living with ovarian cancer: Older women's views. Oncology Nursing Forum, 28(7), 1433-1442.

Gray, R.E., Fitch, M., Greenberg, M., Hampson, A., Doherty, M., \& Lebrecque, M. (1998). The information needs of well, longer-term survivors of breast cancer. Patient Education and Counselling, 33, 245-255.

Hilton, B.A., Crawford, J.A., \& Tarko, M.A. (2000). Men's perspectives on individual and family coping with their wives' breast cancer and chemotherapy. Western Journal of Nursing Research, 22(4), 438-59.

Jenkins, V., Fallowfield, L., \& Saul, J. (2001). Information needs of patients with cancer: Results from a large study in U.K. cancer centres. British Journal of Cancer, 84, 48-51.

Kent, S. (1975). Coping with sexual identity crises after mastectomy. Geriatrics, 30, 145-6.

Lethborg, C.E., Kissane, D., \& Burns, W.I. (2003). It's not the easy part: The experience of significant others of women with early stage breast cancer, at treatment completion. Social Work in Health Care, 37(1), 63-85.

Lewis, F. (2004, August). The impact of cancer on the family. Robert Tiffany Lectureship, 13th International Conference of Cancer Nursing, Sydney, Australia.

Lewis, F.M., \& Hammond, M.A. (1996). The father's, mother's and adolescent's adjustment to a mother's breast cancer. Family Relations, 45, 456-65.

Lewis, F.M., Hammond, M.A., \& Woods, N.F. (1993). The family's functioning with newly diagnosed breast cancer in the mother: The development of an exploratory model. Journal Behavioral Medicine, 16, 351-370.

Lewis, F.M., Woods, N.F., Hough, E.E., \& Bensley, L.S. (1989). The family's functioning with chronic illness in the mother: The spouse's perspective. Social Science Medicine, 29, 126169.

Luker, K.A., Beaver, K., Leinster, S.J., \& Owens, R.G. (1996). Information needs and sources of information of women with breast cancer: A follow-up study. Journal of Advanced Nursing, 23, 487-95. childcare challenges are being handled would provide an opportunity to offer necessary and appropriate referral to community support agencies.

Thirdly, cancer nurses may need to help partners identify and acknowledge the challenges they are facing with regard to their own level of distress, their relationships with their wives, or the communication with wives or children. Important interventions include helping husbands to realize these are expected challenges and learning where assistance can be obtained.

Finally, these results raise questions about how partners are supported routinely. Cancer agencies may need to think about the type of programs they have in place specifically for partners of women with breast cancer. There may be benefit in considering specific educational programs or support programs for partners.

Future research is needed to enlarge our understanding of the impact on male partners of their wives' breast cancer, especially in other cultures. Interventions need to be designed and tested to help male partners.

McGuire, P. (1981). The repercussions of mastectomy on the family. International Journal of Family Psychiatry, 1, 485503.

Moyer, A., \& Salovay, P. (1996). Psychosocial sequelae of breast cancer and its treatment. Annals of Behavioral Medicine, 18(2), 110-125.

Northouse, L. (1988). Social support in patients' and husbands' adjustment to breast cancer. Nursing Research, 37, 91-5.

Northouse, L., \& Swain, M.A. (1987). Adjustment of patients and husbands to the initial impact of breast cancer. Nursing Research, 36, 221-5.

Oberst, M.T., \& James, R.H. (1985). Going home: Patient and spouse adjustment following cancer surgery. Topics in Clinical Nursing, 7, 41-57.

Raupach, J.C., \& Hiller, J.E. (2002). Information and support for women following the primary treatment of breast cancer. Health Expectations, 5(4), 289-301.

Rees, C.E., \& Bath, P.A. (2000). The information needs and source preferences of women with breast cancer and their family members: A review of the literature published between 1988 and 1998. Journal of Advanced Nursing, 31(4), 833-41.

Rees, C.E., Bath, P.A., \& Lloyd-Williams, M. (1998). The information concerns of spouses of women with breast cancer: Patients' and spouses' perspectives. Journal of Advanced Nursing, 28, 1249-1258.

Samms, M.C. (1999). The husband's untold account of his wife's breast cancer: A chronologic analysis. Oncology Nursing Forum, 26(8), 1351-8.

Silverman, D. (2000). Doing qualitative research: A practical guide. London: Sage.

Wellisch, D.K., Jamieson, K.R., \& Pasnau, R.O. (1978). Psychosocial aspects of mastectomy II: The man's perspective. American Journal Psychiatry, 135, 543-546.

Woods, N.F., \& Lewis, F.M. (1995). Living with chronic illness: Women's perspectives on their families' adaptation. Health Care Women International, 16, 135-48.

Yates, P. (1999). Family coping: Issues and challenges for Cancer Nursing. Cancer Nursing, 22(1), 63-71. 